\title{
IMPACT FACTORS IN INTERNET OF THINGS TECHNOLOGY ADOPTION BY USERS: AN EMPIRICAL STUDY
}

\author{
Raad Meshall Al-Tall \\ Business Faculty Management Information System Department, Jordan
}

\begin{abstract}
The goal of the research is to examine the factors determining the adoption of internet of things technologies by users and to establish a proposed model of internet of things technology adoption in Jordan. The study proposed an IoT acceptance model based on the technology model for acceptance, which is known as technology acceptance model (TAM) that consists of four technology factors (IT infrastructure, perceived ease of use, perceived utility, protection) one social context factor which is social influence and two individual user features (perceived behavioral control and perceived enjoyment) in Jordan context. A type of questionnaire survey used for the collection of data and the quantitative statistics and interpretation of questionnaire data used. Data from 370 Jordanian users was used with the use of structural equation modelling to evaluate the research framework. The integrated framework, however, offers more clarity on user behavioral intent towards IoT usage compared to the individual TAM model. This result is consistent with the researcher's point of view, which plays a very important role in evaluating user behavior towards the usage of a modern technology by the protection and IT infrastructure.
\end{abstract}

Key words: Innovation adoption behavior, social context, Internet of Things, TAM, Jordan Cite this Article: Raad Meshall Al-Tall, Impact Factors in Internet of Things Technology Adoption by Users: An Empirical Study, International Journal of Management, 11(12), 2020, pp 2224-2236.

http://iaeme.com/Home/issue/IJM?Volume=11\&Issue=12

\section{INTRODUCTION}

A British technology pioneer who helped develop the idea, coined the term Internet of Things (IoT) in 1999 (Gubbi et al., 2013). The IoT intends to expand daily Internet benefits to goods in the real world - continuous access, remote control, data sharing (Peoples et al., 2013). The IoT contains artefacts with a microchip and a contact antenna at the most basic level (Welle, 2012). Through the use IoT technologies, any real entity in the analogue world can have a unique identification number such as an IP address (Gubbi et al., 2013). They also make Homeland Security passports scannable and allow farecards to be read at underground 
terminals. To keep track of the animals, farmers use chips. The world spent an estimated $\$ 6.37$ billion on RFID chips in 2011 , but by 2014 , this demand would hit over $\$ 20$ billion (RFIDWorld.ca, 2012). The number of items linked to the Internet in 2008 has risen according to the Cisco Internet Business Solutions Company (Welle, 2012). The market research company ABI Research (2013) predicts that by 2020, more than 30 billion devices will become an IoT. With many links, our lives change, and IoT technologies will change the world just as the internet did (Schlick et al., 2013). Jordan plans to accelerate IoT research and to develop an integrated technology framework and a collection of globally recognized standards. The nation is working to help service industries, manufacturing and communication with the IoT, as well as increase software availability to build a significant added value for Jordan (Alzoubi \& Alzoubi, 2020; Al-Momani et al., 2019; Arab-AdvisorGroup, 2015; Asim \& al-Tall, 2016). The country mastered a wide variety of self-developed IoT technology and has applied preliminary steps in various fields including transportation, logistics and finance (Ahmad, 2020; Mohamad, 2020). IoT is however a worldwide developing industry, and Jordan faces many barriers to new ground. While Jordan continues to finance and support IoT development research, technology implementations are still rudimentary and restricted and information safety risks exist (Al-Momani et al., 2019; Meshari \& Ben, 2019). IoT technologies pose questions such as anonymity, protection and access to the data collected by governments and businesses from the perspective of individual users (Evans H. I., 2015). Given the immense investment by Jordan's government and low acceptance rate of IoT products/services, it is imperative that customer acceptance of this modern technique can be understood and the determinants that affect the adoption of IoT users among the IoT needs to be identified. The research into IoT adoption is still in its infancy from the consumer viewpoint. Given the importance of attracting and maintaining IoT users, the factors affecting customer acceptance of IoT products/services need to be identified. A thorough analysis of such factors can lead to a major management impact on how IoT products/services can be more efficiently advertised, leading to greater acceptance of users. Several models to explain the acceptance by users of a new technology have been created. A well-established methodology based on the TAM model, has created a broad range of studies investigating the use and actual use of consumers (Venkatesh et al., 2003; Davis, 1989). In fact, TAM was a parsimonious model with a strong explanatory intensity of user acceptance variance relevant to IT acceptance and use in a wide variety of contexts (HSU et al., 2016; Dijkman et al., 2015; Meshari \& Ben, 2019). Thus, TAM is used as a theoretical basis in this analysis. The research helps us to draw a larger, more systematic image as opposed to previous research, of the drivers of consumer adoption of IoT technologies. A more detailed understanding of customer trust in IoT technologies will help practitioners figure out how to entice customers to use IoT devices even more often and inspire non-users to begin their use In this research, IoT technology practitioners can benefit from a more thorough understanding.

\section{LITERATURE REVIEW}

\subsection{Internet of Things (IoT)}

IoT is a concept based on network that connects all objects to the Internet and enables intelligent detection, tracking, monitoring of locations and management through radio frequency identification (RFID), infrared sensors, global positioning systems, laser scanners, and other sensing devices in the form of a protocol agreed on (Gubbi et al., 2013). The role of IOT in achieving a network link for all management staff and freight so that the management and control of warehouse information is more convenient. The sensor network, the transmission network and the device network can be distinguished by IOT. In addition to the sense-based nerve endings, which recognize objects and collect information sources, the 
sensor Network can identify the sensor objects by means of a two-dimensional RFID code. Input and output management terminals are the applications network, and their function is to meet user requirements (individuals, organizations) to achieve the intelligent use of IOT (Uckelmann et al., 2011). With the IoT technology, performance is high across many industries and benefits are important for users of them. Users will benefit from IoT technologies in smart refrigerators for example, which autonomously track the food and beverage intake and re-order items (Sundmaeker et al., 2010). IoT technologies can impact the conduct of users in many areas of users' everyday life in this context (Tan \& Wang, 2010). Transmission networks play a role in data transmission and in computation, as do human and neural networks and brain systems that convey and process sensor information network data through the Internet, radio and TV networks, communication networks and cloud computing platforms. Existing studies have looked at the technical problems of IoT implementation (LiX $\&$ Wang, 2013). The main challenges for user-based applications include for instance, researchers (Dijkman et al., 2015; Evans H. I., 2015) finding problems in security and privacy. The architecture of IoT was explained by Uckelmann et al. (2011). The IoT best practices (e.g. HTML, JavaScript, PHP) were defined by Guinard et al., (2011) and proposed several prototypes that use Web concepts that link environment sensor nodes, energy monitoring systems and RFID tagged objects into the Web. A great many earlier research has concentrated on the design and usage of IoT technology from the point of view of the company or industry (Schlick et al., 2013) while little consideration has been given to understanding how individual customers adopt IoT technologies (LiX \& Wang, 2013). Moreover, past research has still not examined the impacts on the adoption of IoT technologies by users of technical characteristics, the social background and individual user characteristics. Given the high practical relevance and lack of empirical previous work, current research aims to build and test an integrative model of factors which will decide whether IoT technology is appropriate to users.

\subsection{Technology Acceptance Model}

The research model used in this report is based on the TAM. The TAM was suggested as a fundamental mechanism to track human values, behaviors and intentions from external influences. TAM also estimated that the attitude of the human being towards information systems is a product of two core principles (Davis, 1989). These include the perceived benefit (PU) of using such technologies to enhance the concepts as individual work performance. The consumer views the system favorably as the system promotes job efficiency (attitude). This positive attitude makes the system more user friendly. PEOU refers to the comfort level of using the technology, although simple to use. The PEOU is viewed by individuals as a working aspect of the system. And these are the two effects on the thinking of the personality and the preceding attitude. These two mechanisms establish the positive or negative attitude to technology acceptance. The sensitivity to external factors correlating with information system and climate requirements fosters these two dimensions. The TAM protocol led to the use of a given information system controlled by behavioral intent that influenced each other by each other through the attitude towards utility of both people and technology. Nevertheless, considering their attitude towards the system, people communicate their intention of embracing the information system when they know its utility (Venkatesh et al., 2003). Many studies have shown the utility of the construct in the TAM model as the most influential since it determines user understanding of the meaning of IT. In the field of transport, perceived utility has a major impact on technology users' status and behavior. The presumed utility encourages the actions of users embracing the electronic vehicle. The attitude and intention of users to embrace the e-tolling system have a considerable impact. The TAM is a framework in information technology to understand the use of new technologies by users, 
particularly in the workplace and has been tested in older populations. The idea is that an intention of a person to use (acceptance of technology) and to use (actual use a technique is based on the person's understanding of the utility and ease of use of the technology. Simply put, users are more likely to implement new UX design technologies (ie, usable, useful, desirable, and credible). The TAM indicates that expectations of usability and ease of use can be mediated by external variables including variations, device features, social factors, and ease of use. Perceived ease of use is described as the extent to which an individual believes it is free of effort to use a particular system." There is strong to determine how to shape the customer's context, the device practicality will increase and that will inevitably affect the behavioral purpose of the framework (Venkatesh et al., 2003; Davis, 1989).

Although prior study has shown that TAM is a parsimonious and strong model, TAM uses only two users' convictions perceived utility, perceived ease of use to describe the acceptance of consumers. However other considerations, like the views of other main people (social impact), may also affect the acceptance of consumers for the adoption of IoT (Venkatesh et al. ,. V., 2013). In addition, while users have a strong intention of performing behavior, they cannot do so without the requisite resources and abilities (PBC) (Ajzen, 2011). The TAM model cannot therefore clarify significant variables that influence consumer acceptance of IoT technology in an appropriate and reliable way. Therefore, the study argue that certain extensions to the model are appropriate if IoT technology is to be accepted. Hande et al., (2019) claimed that factors important particularly to the particular technology under investigation should be extended to include the TAM. Marketing research indicates that PBCs are main factors affecting customer acceptances of new technology: pleasure, confidence, social impact (LEE et al., 2018; Okhan, 2018; Shang et al., 2012). Authors (Ajzen, 2011; Meshari \& Ben, 2019)for example indicated that the use of technology could affect factors such as fun and PBC. Koufaris, (2002) have also improved TAM with the pleasure of eshopping within the customer behavioural literature. Furthermore, social influence has been included in TAM and has shown a substantial impact on customer technical purpose, as LEE et al., (2018). Li et al., (2011) proposed to incorporate confidence in the TAM, a model which integrates previous works. The results showed that related to other models laid down, the integrated model provides improved comprehension of consumers' purpose. Similarly, by adding more ties, from perceived faith through intention to use, (Zhang \& Mao, 2008; Jaafreh, 2018) further expanded TAM.

Researchers have suggested improvements to enhance the predictive capacity of TAM, by introducing additional historical factors which are considered extremely important for modern technology (Svendsen et al., 2013). Thus, this study incorporates security, IT infrastructure, social impact, perceived fun, and behavior control into TAM to better understand how IoT is embraced by users through these discussions. The integrated TAM version involves previous work in a model that examines the motivating forces of individuals' ability to use IoT technologies from a technical viewpoint, a social context, and the unique characteristic of individual users. The TAM is considered a starting point for our research and is expanded with further constructs essential to the acceptance of IoT technology. This analysis therefore takes account of the need for additional research, which extends and deepens TAM by adding new variables and explaining and re-conceptualizing existing variables in the model (AlMomani et al., 2019; Bagozzi, 2007). 


\section{RESEARCH HYPOTHESES AND CONCEPTUAL FRAMEWORK}

This study proposes a user model that integrates variables of perceived usefulness, perceived ease of use, protection, IT infrastructure, social effect, perceived pleasure, and perceived conduct regulation for compelling purposes, and two components that influence the actions of use. Figure (1) displays the proposed IoT acceptance/use model.

\subsection{Perceived usefulness}

A failure to articulate a specific advantage to potentials may be one of the key reasons for the slow proliferation of IoT technologies applications. According to the principle of innovation diffusion (IDT), consumers can only embrace innovations if such innovations provide a specific benefit in comparison with existing solutions (Rogers, 1995). This view is reflected in the sense of TAM in the concept of perceived utility. The perceived utility in this study is close to the predicted performance of the united acceptability and technology usage theory (UTAUT) and the relative advantage of IDT (Venkatesh et al. ,. V., 2013). When using the technology, it refers to users' feelings about improved results. IoT technology can provide quicker processes in retail stores, offer less queuing time and boost customer perceived service quality. Also, IoT technologies applied to the railway section may provide maintenance workers with information from the transponders mounted on the trains through a mobile reader to determine whether or not maintenance is required (Okhan, 2018). An inventory is automatically retained by time maintain schedules are needed for a duration or extent on age Consequently, IoT innovations are likely to be highly considered to be useful. Extensive research has shown that convenience in services improves customer loyalty and affects consumer intent. IoT innovations can reach a higher rate of adoption if they are able to facilitate the everyday lives of consumers. The TAM notes that the perceived utility is an important determinant of behavioral purpose on IT (Davis, 1989) and thus suggests the following: The perceived usefulness is an important determinant of the conductual intention to use IT:

\section{H1. Perceived usefulness has a positive impact on the behavioral intention to use IoT technologies.}

\subsection{Perceived ease of use}

Perceived ease of use is similar to the UTAUT effort and complexity of the IDT (Venkatesh et al., 2013). It deals with the efforts of the users as they use IoT technology/services. To adopt IoT by IoT users, IoT needs to be fascinating. Several earlier studies confirm that perceived ease of use is an integral influencer of moral values of the technology to (Davis, 1989; LEE et al., 2018). The perceived ease of use has an effect on the perceived utility according to TAM and UTAUT (LEE et al., 2018; Venkatesh et al., 2013). We propose:

\section{H2. Perceived ease of use has a positive impact on the behavioral intention to use IoT technologies.}

\subsection{Perceived Security}

In daily life, IoT services provide new protection and privacy issues. There is considerable concern about the protection of data stored in IoT environments (Sundmaeker et al., 2010; Lingling \& Xuesong, 2014). Perceived security is characterized as the degree to which an individual believes that the use of a specific application is risk-free (Lingling \& Xuesong, 2014). The current research addresses perceived protection from a wider perspective, taking into account not only the technological aspects, such as confidentiality and authentication 
(Hande et al., 2019), but also the holistic sense of security and well-being of an individual in the IoT setting (Lingling \& Xuesong, 2014). Studies warn that security issues are a major obstacle to fresh big data adoption (Ahmed et al., 2020; Kshetri, 2014). It is therefore rational to conclude that the perceived protection of the IoT would affect attitudes towards it and its adoption intentions:

\section{H3. Perceived security has a positive impact on the behavioral intention to use IoT technologies.}

\subsection{IT Infrastructure}

IT infrastructure is the foundation for the provision of IoT services to users where and when necessary IT infrastructure is described by Duncan, (1995) as a common collection of tangible IT resources that forms the foundation for corporate applications. These include technology frameworks (hardware and operating systems), technology for networks and telecom, data and main software's. Weill, (1993) notes that IT infrastructure is the basis on which business and functional capabilities can be built. The IT infrastructures are referred to as the part of knowledge that the company intends to exchange and as the basis upon which particular business operations and computer applications are developed by Davenport \& Linder, (1994). Organizations that quickly adjust their processes will find convergence of IT and OT will occur faster. In order to assess the impact of IT infrastructure on IoT systems, we have taken the following measures: the regain in the extent in that IT systems are decentralized around the business (Ehiea \& Michael, 2020), the degree to which modern technologies are adapted to older technologies (Ehiea \& Michael, 2020).

\section{H4. IT infrastructure has a positive impact on the behavioral intention to use IoT technologies.}

\subsection{Social Influence}

In the assessment of the reception of technological trends, a decision-making official's social climate cannot be overlooks. In decision-making, the social context plays a significant part (Hsu \& Lu, 2004). In an early stage of production or dissemination, goods, and services in particular. Most users here lack accurate usage information. Therefore, the importance of individual product evaluations of the social network opinions is growing. In line with Venkatesh et al. (2013), we integrate the social context of our research model by including the element of social influence, identified as the impression of users whether other significant individuals felt they were involved in the behavior. Subjective norm for rational action theory (TRA) parallels social control (Venkatesh et al., 2013 (Lingling \& Xuesong, 2014)). Influence on IoT technologies and services from friends, families, or even media like television may influence the purpose of users. Many people use IoT mobile devices because they are depicted in the media as a trend. There has been significant social impact in the field of IS. Davis et al. (1989), for example, stressed the importance of social power in the acceptance and use of IT. Ehiea \& Michael, (2020) concluded that a major effect of social influence was the desire of customers to take up mobile trading. We contend that according to previous studies:

\section{H5. Social influence has a positive influence on the behavioral intention to use IoT technologies.}

\subsection{Perceived Enjoyment}

Furthermore, the original TAM is extended by the supposed gain of IoT technology. The pleasure perceived as a key reason for users to embrace new technology was found (Lingling 
\& Xuesong, 2014). It is defined as to how fun is the activities of the implementation of IoT technologies, other than any anticipated effects on performance (Davis, 1989). Users are naturally inspired to embrace IOT innovations because they can offer fun and pleasure. Previous studies have shown that the satisfaction of shopping is a significant determinant of why customers shop (Ehiea \& Michael, 2020; Lu \& Su, 2009). In addition, studies of the role of pleasure in mobile trade indicated that it is necessary for usage purposes and conduct to enjoy (Lingling \& Xuesong, 2014).

\section{H6. Perceived enjoyment has a positive influence on the behavioral intention to use IoT technologies.}

\subsection{Perceived behavioral Control}

$\mathrm{PBC}$ is an additional factor that encourages people's participation in the hunt. It is analogous to encouraging UTAUT conditions and defines the experience of users when they have the tools, power, and sense of control to conduct themselves effectively. For the operation of IoT systems/devices, users need the basic skills. When for example mobile IoT devices are used by the rail personnel to manage the train's mechanical parts and to track the tempering of the wheels, fear of control and negative assessment of the IoT technology could be triggered if they do not have the capacities to operate the IoT systems. The positive function of PBC has been supported by (Lu \& Su, 2009; Lingling \& Xuesong, 2014; Ahmed et al., 2020). Purpose to act. Therefore, we pose this in the sense of IoT technology: Kim et al., (2008) have suggested a major effect of perceived gratification on intent to use short messaging. We postulate that by applying this to the sense of IoT adoption:

\section{H7. PBC has a positive influence on the behavioral intention to use IoT technologies.}

\subsection{Behavioral Intention and Usage Behavioral}

The purpose can be understood as a user's intensity that is prepared to perform one action Jaafreh, (2018). The purpose of actions refers to a subjective decision on the future. Purpose of use defines personal expectations for a certain subject, such as behavior, thinking or perception (Davis, 1989). Venkatesh et al. (2013) said that the attitude towards actual use is characterized as subjective knowledge of, actions and personal emotion, and preference. Ahmed et al., (2020) and $\mathrm{Lu} \mathrm{\&} \mathrm{Su,} \mathrm{(2009)} \mathrm{argued} \mathrm{that} \mathrm{users} \mathrm{are} \mathrm{heavily} \mathrm{influenced} \mathrm{by} \mathrm{the}$ purpose of using and the actual usage of IoT. Therefore, we pose this in the sense of IoT technology:

\section{H8. Behavioral intention has a positive impact on Usage Behavioral of IoT technologies.}

\section{METHODOLOGY}

This research explored the behavioral intentions of users to use IoT technologies. Model adoption of innovations, social context element and two user features used as a research framework. An observational survey approach for collecting data administered by personal transmission and by e-mail is used to determine the study objectives. Quantitative statistics and questionnaire analyses were used in this analysis. There are two parts of the survey instrument. Personal and demographic information is provided in the first segment. In the second section of the survey questionnaire the related studies have been developed and have been checked. Item scales that adjust them to the user context in Jordan using minor modifications. The survey has been conducted in Jordan between November and December 2019, through schools, academia, research institutes, companies, and internet cafes. Data from current IoT applications users in the cities of Amman and Northern Jordan were collected, 
with IoT technology relative to other regions. 484 questionnaires were originally compiled for feedback from the 2000 questionnaires distributed. 76 of the questionnaires obtained were eventually deleted because of lack of data or invalid answers. Ultimately, the empirical study was based on 410 questionnaires. The study used Lau et al., (2010) approach to resolve the possible non-response bias and used t-test to compare the average scores of the initial ten $\%$ of respondents and the last ten percent of respondents for key variables. There was no substantial difference between median values in the two response groups in the results of the t-test. It was decided, therefore that the non-response factor in this study was not a major concern.

\subsection{Measures}

The objects for measuring the study focal structures were taken from earlier studies and slightly altered to fit the particular study context. These papers were first translated by a researcher into Arabic. Then another researcher returned them to English in order to ensure accuracy. It was tested by 20 people with IoT technology expertise when the system was built. We then used their comments to update several items in order to enhance transparency and understandability. The scales of Davis (1989) have been modified to capture the perceived utility and ease of use. Things of perceived usefulness reflect the increased performance and comfort through the use of advanced technologies such as IoT. Things of perceived ease of use reflect the ease of learning to use advanced technologies such as IoT devices or the skillful use of them. Protection items were adapted from Shin and Yong (2017) and IoT services provide new perceived security problems in everyday life Ehie and Michael (2020) adapted IT infrastructure items and enabled a foundation capable of providing IoT services to users where and when appropriate. Mathieson adopted objects of social power and PBC from (Venkatesh et al., 2013). Things of social influence reflect the influence on the adoption actions of individuals important to the consumer. PBC items represent the user's resources and skill. Moon and Kim (2001) adapted objects of perceived enjoyment that represent the fun, pleasure, and enjoyment of using advanced technology such as IoT devices. Behavioral intent adapted objects from Venkatesh (2013). Five-point scales ranging from strongly disagree (1) to strongly agree (5) were used to test all things (Table 1)

\section{MEASUREMENT MODEL}

Overall fitting of the measurement model was excellent (X2/df=1.279, GFI $=0.997$, $\mathrm{CFI}=0.895$, RMSEA $=0.029)$. The overall measuring model provided an excellent match. The standardized factor loadings, average variance extracted (AVE), and composite reliabilities (CRs) were tested to determine convergent validity. All factor loadings were greater than 0.7, as shown in Table I, and the critical ratio showed that all loadings were significant at 0.001 . All AVEs and CRs, respectively, reach 0.5 and 0.7 . The scale has a strong convergent validity, thus (Bagozzi and Yi, 1988; Gefen et al., 2000). Furthermore, all a-values were greater than 0.7, indicating strong reliability (Nunnally, 1978).

Table 1 Results of the measurement model

\begin{tabular}{|l|l|l|l|l|l|}
\hline \multicolumn{1}{|c|}{ Construct } & \multicolumn{1}{c|}{$\begin{array}{c}\text { Stand. } \\
\text { loadings }\end{array}$} & $\begin{array}{c}\text { Critical } \\
\text { ratio }\end{array}$ & AVE & CR & \\
\hline Perceived usefulness (PU) & \multicolumn{1}{|c|}{} & 0.81 & 0.85 & \\
\hline PU1 & 0.75 & $24.90^{*}$ & & & \\
\hline PU2 & 0.76 & $24.87^{*}$ & & & \\
\hline PU3 & 0.79 & $23.85^{*}$ & & & \\
\hline PU4 & 0.80 & $21.86^{*}$ & & & \\
\hline PU5 & 0.74 & $20.96^{*}$ & & 0.92 & \\
\hline Perceived ease of use (PEOU) & & & 0.79 & & \\
\hline PEOU1 & 0.86 & $27.55^{*}$ & & & \\
\hline PEOU2 & 0.87 & $26.67^{*}$ & & & \\
\hline PEOU3 & 0.81 & $28.21^{*}$ & & & \\
\hline
\end{tabular}




\begin{tabular}{|c|c|c|c|c|c|}
\hline PEOU4 & 0.80 & $25.33 *$ & & & \\
\hline PEOU5 & 0.85 & $30.51 *$ & & & \\
\hline IT Infrastructure (ITI) & & & 0.83 & 0.78 & 0.0 .95 \\
\hline ITI1 & 0.90 & $23.14 *$ & & & \\
\hline ITI2 & 0.91 & $29.13 *$ & & & \\
\hline ITI3 & 0.89 & $23.52 *$ & & & \\
\hline ITI4 & 0.88 & $24.74 *$ & & & \\
\hline Perceived security (PS) & & & 0.72 & 0.78 & 0.89 \\
\hline PS1 & 0.70 & $25.35 *$ & & & \\
\hline PS2 & 0.73 & $18.97 *$ & & & \\
\hline PS3 & 0.71 & $19.95 *$ & & & \\
\hline Social influence (SI) & & & 0.82 & 0.80 & 0.93 \\
\hline SI1 & 0.78 & $34.54 *$ & & & \\
\hline SI2 & 0.76 & $33.53 *$ & & & \\
\hline SI3 & 0.78 & $32.34 *$ & & & \\
\hline SI4 & 0.82 & $30.45 *$ & & & \\
\hline Perceived enjoyment (PE) & & & 0.73 & 0.81 & 0.92 \\
\hline PE1 & 0.80 & $31.12 *$ & & & \\
\hline PE2 & 0.82 & $30.14 *$ & & & \\
\hline PE3 & 0.78 & $34.05 *$ & & & \\
\hline PE4 & 0.75 & $30.09 *$ & & & \\
\hline $\begin{array}{l}\text { Perceived behavioural control } \\
\text { (PBC) }\end{array}$ & & & 0.77 & 0.88 & 0.90 \\
\hline $\mathrm{PBC} 1$ & 0.74 & $23.68 *$ & & & \\
\hline $\mathrm{PBC2}$ & 0.91 & $29.29 *$ & & & \\
\hline $\mathrm{PBC} 3$ & 0.79 & $21.35 *$ & & & \\
\hline PBC4 & 0.81 & $23.80 *$ & & & \\
\hline $\begin{array}{l}\text { Behavioral intention to use } \\
\text { (BI) }\end{array}$ & & & 0.87 & 0.84 & 0.96 \\
\hline BI1 & 0.86 & $23.19 *$ & & & \\
\hline BI2 & 0.87 & $27.11 *$ & & & \\
\hline $\mathrm{BI} 3$ & 0.92 & $20.16^{*}$ & & & \\
\hline BI4 & 0.88 & $22.52 *$ & & & \\
\hline BI5 & 0.91 & $33.33^{*}$ & & & \\
\hline Usage behavior (UB) & & & 0.85 & 0.79 & 0.97 \\
\hline UB1 & 0.91 & $35.16^{*}$ & & & \\
\hline UB2 & 0.90 & $33.07 *$ & & & \\
\hline UB3 & 0.93 & $32.10 *$ & & & \\
\hline
\end{tabular}

Two approaches were used to determine the discriminating validity of the systems. Firstly, the discrimination is accomplished when the square root of the AVE is greater than the correlation between two composite constructions in respect of the process employed by Fornell and Larcker (1981). The square roots of AVE, as shown in Table II, are consistently larger than the off diagonal correlations. Secondly, based on the work done by O'Cass and Ngo (2007), discriminating validity is indicated when the corresponding association (outdiagonal entries) is not more than the reliability value of two structures. Results showed in Table (2) show all correlations (0.312-0.632), which have strong discriminatory validity, to be less than their respective reliability $(0.798-0.896)$.

Table 2. Discriminant validity assessment results

\begin{tabular}{|l|l|l|l|l|l|l|l|l|l|}
\hline & PU & PEOU & ITI & PS & SI & PBC & BI & UB & PE \\
\hline PU & $\mathbf{0 . 8 5 4}$ & & & & & & & & \\
\hline PEOU & $\mathbf{0 . 8 8 5}$ & $\mathbf{0 . 7 3 0}$ & & & & & & & \\
\hline ITI & $\mathbf{0 . 8 8 9}$ & $\mathbf{0 . 7 4 5}$ & 0.632 & & & & & & \\
\hline PS & $\mathbf{0 . 8 7 5}$ & $\mathbf{0 . 6 5 4}$ & 0.432 & 0.971 & & & & & \\
\hline SI & $\mathbf{0 . 7 9 8}$ & $\mathbf{0 . 6 6 9}$ & 0.432 & 0.858 & 0.791 & & & & \\
\hline PBC & $\mathbf{0 . 8 7 1}$ & $\mathbf{0 . 6 7 1}$ & 0.423 & 0.891 & 0.529 & 0.553 & & & \\
\hline BI & $\mathbf{0 . 7 8 8}$ & $\mathbf{0 . 7 5 9}$ & $\mathbf{0 . 6 5 5}$ & 0.684 & 0.417 & 0.831 & 0.525 & & \\
\hline UB & $\mathbf{0 . 8 9 6}$ & $\mathbf{0 . 6 8 2}$ & 0.312 & 0.745 & 0.490 & 0.732 & 0.863 & 0.728 & \\
\hline PE & & & & & & 0.861 & 0.772 & 0.818 \\
\hline
\end{tabular}

Two experiments were performed to investigate the popular bias. First, we did not find a single factor using the one-factor Harmon test (Podsakoff et al. 2003) and the first factor represented $25,254 \%$ of the $66,301 \%$ of the explicit variance respectively. Second, all objects were modelled as the indicators of a system impact factor and the model was re-estimated (Malhotra et al., 2006). There was low health ( $\mathrm{x} 2 / \mathrm{df}=14,365, \mathrm{CFI}=0,725, \mathrm{GFI}=0,658$, 
TLI=0,436, RMSEA=0,175). The results were not strong enough. We conclude with both tests that in this research the issue of the traditional method bias was not apparent. The variation explained was $85 \%$ respectively of behavioral intentions.

\subsection{Structural Model}

Structural Equation Modeling (SEM) techniques were used to evaluate the causality between the historical factors and the intention of users to use IoT technologies. Fit indices $(\mathrm{x} 2 / \mathrm{df}=$ 1.210 , CFI $=0.962$ ) indicated that the set of data would be acceptable. The results indicate that the data was acceptable. The results The Fit indices were acceptable. The data set was acceptable (Schumacker and Lomax, 2004). As listed in figure 2, the perceived perceived performance use $(b=0.76, p, 0.011)$ has a strong impact on the behavioral intention to use the IoT technologies, their perceived performance use $(b=0.53, p, 0.012)$, their IT infrastructures $(b=0.30, p, 0.000)$, their perceived awareness $(b=0.41, p, 0.003)$, their social effect $(b=$ $0.59, \mathrm{p}, 0.000)$, their perceptive perception of their perceived behavioral control $(\mathrm{b}=0.62, \mathrm{p}$, $0.000)$ There are also important and good effects in use of behavioral intent $(b=0.71, p 1$, 0.000 ) in output on and outcome for $\mathrm{H} 8$, respectively.

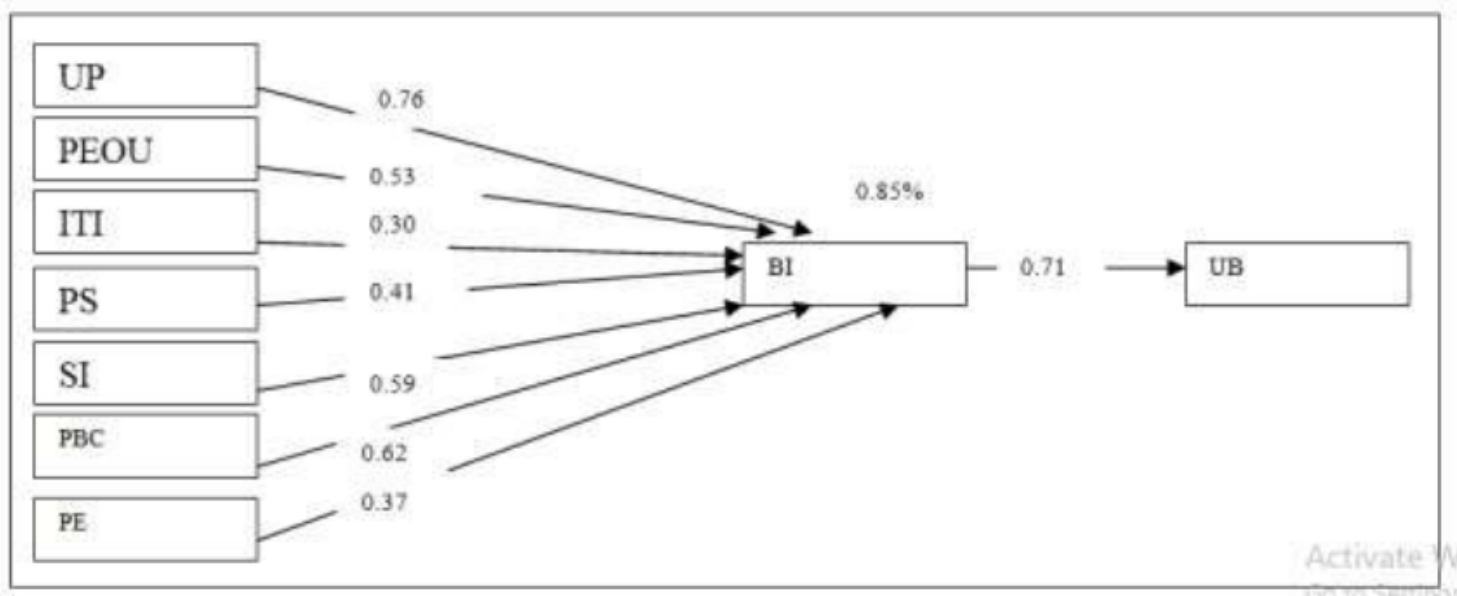

Figure 2. Structural model showing results of analysis

\section{DISCUSSION}

The research will examine in an integrated way the factors influencing the acceptance by users of IoT technology. The result demonstrates the solidity of the TAM and describes users' actions in terms of technical acceptance under IoT. The study suggests that the users' perception of utility, ease of use, regulation of behavior, enjoyment and social influence predict their purpose by proposing an expanded TAM to incorporate 2 technologies (safety and IT infrastructure), one social context variable (i.e. social influence) and 2 individual usercharacteristic variables (i.e. perceived appreciation and PBC). When compared to other variables of conviction, utility arises from the direction coefficients of antecedents of the behavioral purpose towards IoT technologies. This supports prior TAM research finding it useful that one is the primary driver of the use of a technology, while ease of use, trust and enjoyment are secondary factors (Davis, 1989). However, this does not reflect findings from previous studies which observed a greater impact of pleasure on conduct than ease of use and/or utilities in the context of behavior (Lingling \& Xuesong, 2014). This incoherence indicates that more research is required. For example, Ahmed et al., (2020) suggested the distinct significance of usability, usability, and pleasure in the various atmospheres (e.g. Hedonic/utilitarian environments), which in turn influence purpose differently. Moreover, the 
second biggest effect on behavioral intent is social impact. The study showed that perceived pleasure positively affects acceptance of the new technology with the help of Ehiea \& Michael, (2020) assumption.

\section{IMPLICATIONS}

Theory and experience have consequences for this research. The theoretical contribution is theoretical, from a popular viewpoint, which includes technical expectations (Security, IT infrastructure perceived utility, ease of use perceived), variable social context (social influence) and user characteristics, which affect the user's acceptance of IoT technologies (perceived enjoyment and PBC). The IoT technology background, which varies from other information structures, successfully lines TAM with the frameworks of social forces, fun and PBC and the TAM. With this integrated model, the market adoption of IoT technologies in Jordan is best understood while remaining the parsimony of the model. The research relates to existing customer and marketing awareness in two ways.

\section{DIRECTIONS FOR FUTURE RESEARCH AND RESEARCH LIMITATIONS}

There are some drawbacks to this study. First a cross-sectional research design is not as descriptive as a longitudinal research design. Therefore, future studies should use longitudinal data in order for the time sequence of interactions between structures to be further studied. Second, while the study was intended to explore the field of IoT technologies' consumer adoption in emerging economies, only one such economy was based in Jordan. Given that the socio-cultural values, government regulations and business practices may be very different than in other developed economies, it is recommended that future research extend IoT acceptance limits in other developing nations (such as the Arab country) to verify the validity of the model laid down in this report. In order to increase the generalizability of a research model, future research requires replicating the study with different IoT product categories. Qualitative research is also being promoted to better understand the perspectives of customers on IoT technology in future research

\section{REFERENCES}

[1] Ahmed et al. (2020). Predicting IoT Service Adoption towards Smart Mobility in Malaysia: SEM-Neural Hybrid Pilot Study. International Journal of Advanced Computer Science and Applications, Vol. 11, No. 1,524-535.

[2] Ajzen, I. (2011). The theory of planned behaviour: reactions and reflections, Psychology \& Health, Vol. 26 No. 9, pp. 1113-1127.4.

[3] Al-Momani et al. (2019). Factors that Influence the Acceptance of Internet of Things Services by Customers of Telecommunication Companies in Jordan. Organizational and End User Computing.

[4] Alzoubi, S., \& Alzoubi, A. (2020). Determinants of E-Learning Based on Cloud Computing adoption: Evidence from a Students' Perspective in Jordan; Vol. 29, No. 4, (2020), pp. 13611370, Published by IJAST.

[5] Arab-Advisor-Group. (2015). Internet of Things "IoT" services in the Arab World. Retrieved March 8, 2020 from, at: http://www.arabadvisors.com/reports/item/15542.

[6] Asim, V., \& al-Tall, R. M. (2016). Electronic Commerce deployment, motivations and satisfaction: A qualitative perspective. International Journal of Computer Science and Information Security Vol. 14, No. 10. 
[7] Davenport, T., \& Linder, J. (1994). Information management infrastructure: the new competitive weapon. Proceedings of the 27th Annual Hawaii International Conference on Systems Sciences Vol. 27, 885-899.

[8] Davis, F. D. (1989). Perceived usefulness, perceived ease of use and user acceptance of information technology", MIS Quarterly, Vol. 13 No. 3, pp. 319-340.

[9] Dijkman et al. (2015). Business models for the Internet of Things. International Journal of Information Management, 35(6), 672-678.

[10] Duncan, N. (1995). Capturing flexibility of information technology infrastructure: a study of resource characteristics and their measures. Journal of Information Systems 12 (2), 37-57.

[11] Ehiea, A., \& Michael, C. (2020). Understanding the influence of IT/OT Convergence on the adoption of Internet of Things (IoT) in manufacturing organizations: An empirical investigation.

[12] Evans, H. I. (2015). Barriers to Successful Implementation of the Internet of Things in Marketing Strategy, 5(9).

[13] Gubbi et al. (2013). Internet of things (IoT): a vision, architectural elements, and future directions", Future Generation Computer Systems,Vol. 29 No. 7, pp. 1645-1660.

[14] Guinard et al. (2011). From the internet of things to the web of things: resource-oriented architecture and best practices", in Uckelmann, D., Harrison, M.and Michahelles, F. (Eds), Architecting the Internet of Things, Springer, Berlin, pp. 97-129.

[15] Hande et al. (2019). Consumers' Acceptance of Internet of Things Technology, Istanbul Gelisim University Journal of Social Sciences, 6 (2), October 2019, pp. 351-371.

[16] HSU et al. (2016). An empirical examination of consumer adoption of Internet of Things services: Network externalities and concern for information privacy perspectives. Computers in Human Behavior, 516-527.

[17] Hsu, C. L., \& Lu, H. P. (2004). Why do people play on-line games? An extended TAM with social influences and flow experience, Information \& Management, Vol. 41 No. 7,

[18] Jaafreh, A. (2018). The Effect Factors in the Adoption of Internet of Things (IoT) Technology in the SME in KSA: An Empirical Study. International Review of Management and Business Research Vol. 7 Issue.1.

[19] Kim et al. (2008). An examination of factors influencing consumer adoption of short message service (SMS)", Psychology \& Marketing, Vol. 25 No. 8, pp. 769-786.

[20] Koufaris, M. (2002). Applying the technology acceptance model and flow theory to online consumer behaviour, Information Systems Research, Vol. 13 No. 2, pp. 205-223.

[21] Kshetri, N. (2014). Big data's impact on privacy, security and consumer welfare, Telecommunications Policy, Vol. 38 No. 11, pp. 1134-1145.

[22] Lau et al. (2010). Effects of suppliers and customer integration on product innovation and performance: empirical evidence in Hong Kong manufacturers, Journal of Product Innovation Management, Vol. 27 No. 5, pp. 761-777.

[23] LEE et al. (2018). The adoption of virtual reality devices: The technology acceptance model integrating enjoyment, social interaction, and strength of the social ties. Telematics and Informatics.

[24] Li et al. (2011). Smart Community: An Internet of Things Application. IEEE Communications Magazine, 68-75.

[25] Lingling, G., \& Xuesong, B. (2014). A unified perspective on the factors influencing consumer acceptance of internet of things technology. Asia Pacific Journal of Marketing and Logistics Vol. 26 No. 2,pp. 211-231, 1355-5855. 
[26] LiX, X. J., \& Wang, A. (2013). Architecture and existing applications for internet of things, Applied Mechanics and Materials, Vol. 347 No. 1, pp. 3317-3321.

[27] Lu, H., \& Su, P. Y. (2009). Factors affecting purchase intention on mobile shopping web sites, Internet Research, Vol. 19 No. 4, pp. 442-458.

[28] Meshari, A., \& Ben, S. (2019). Internet of Things for Healthcare Purposes: Extending the Technology Acceptance Model for Saudi Arabia Patients IJCSNS International Journal of Computer Science and Network Security, VOL.19 No.2, February 2019.

[29] Okhan, M. K. (2018). Five acts of consumer behavior: A potential security and privacy threat to Internet of Things. IEEE International Conference on Consumer Electronics. IEEE.

[30] Peoples et al. (2013). Performance evaluation of green data centre management supporting sustainable growth of the internet of things, Simulation Modelling Practice and Theory, Vol. 34, pp. 221-242.

[31] Rogers, E. M. (1995). Diffusion of Innovations, The Free Press, New York, NY.

[32] Schlick et al. (2013). IoT Applications - Value Creation for Industry, River Publisher, Aalborg.

[33] Shang et al. (2012). Internet of things (IoT) service architecture and its application in ecommerce, Journal of Electronic Commerce in Organizations, Vol. 10 No. 3,pp. 44-55.

[34] Sundmaeker et al. (2010). Vision and Challenges for Realising the Internet of Things: CERPIoT - Cluster of European Research Projects on the Internet of Things, European Commission - Information Society and Media DG, Brussels.

[35] Tan, L., \& Wang, N. (2010). Future internet: the internet of things, Advanced Computer Theory and Engineering 2010 Proceedings of the International Conference, Chengdu,China, IEEE, Washington, DC, pp. 376-380.

[36] Uckelmann et al. (2011). An architectural approach towards the future internet of things", in Uckelmann, D., Harrison, M. and Michahelles, F. (Eds), Architecting the Internet of Things, Springer, Berlin, pp. 1-24.

[37] Venkatesh et al. (2003). User acceptance of information technology: toward a unified view", MIS Quarterly, Vol. 27 No. 3, pp. 425-478.

[38] Venkatesh et al., V. (2013). Consumer acceptance and use of information technology: extending the unified theory of acceptance and use of technology, MIS Quarterly, Vol. 36 No. 1, pp. 157-178.

[39] Weill, P. (1993). The role and value of information technology infrastructure: some empirical observations. In: Banker, R., Kauffman, R., Mahmood, M.A. (Eds.), Strategic Information Technology Management: Perspective on Organizational Growth ad Competitive Adpp.547572.

[40] Welle, D. (2012). Internet of Things' Holds Promise, But Sparks Privacy Concerns, availableat: $\quad$ www.dw.de/internet-of-things-holds-promise-but-sparks-privacy-concerns/a15911207-1(accessed July 14, 2013).

[41] Zhang, J., \& Mao, E. (2008). Understanding the acceptance of mobile SMS advertising among young Chinese consumers", Psychology \& Marketing, Vol. 25 No. 8, pp. 787-805. 